\title{
CENTRO DE ARTE: MOTOR DE TRANSFORMACIÓN DE LA METRÓPOLIS CONTEMPORÁNEA Caso Cerrillos, Santiago de Chile ${ }^{1}$.
}

\author{
ART CENTER: TRANSFORMATION ENGINE OF \\ CONTEMPORARY METROPOLIS. \\ Case of Cerrillos, Chile's Santiago.
}

\author{
Gallardo Frías, Laura; \\ Departamento Arquitectura, Universidad de Chile. lauragallardofrias@uchilefau.cl \\ Toledo Jofré, María Isabel \\ Universidad Diego Portales. maria.toledo@udp.cl \\ Figueroa Garavagno, Consuelo \\ Universidad Diego Portales. consuelo.figueroa@udp.cl
}

\begin{abstract}
RESUMEN
Los centros de arte contemporáneo son considerados piezas motoras de transformación urbana, lo que se ha constatado en numerosas ciudades de todo el mundo. Por ello, el objetivo de este artículo es analizar el Centro Nacional de Arte Contemporáneo Cerrillos, único de su tipo en Chile. Con este fin, se despliega una estrategia metodológica multidisciplinaria y multimétodo que permite el estudio de un caso institucional. Como resultado se describe el centro en función de cuatro dimensiones: histórica, urbana, arquitectónica y sociocultural. En la discusión se analiza la conectividad, la accesibilidad, la legibilidad, los recorridos y permanencias y la flexibilidad. Se concluye que, si bien se requiere potenciar algunos elementos secundarios, este centro opera como un motor de transformación de un sector desvalorizado de la ciudad.
\end{abstract}

Palabras clave: Centro de arte contemporáneo, motor de transformación, proyecto urbano y proyecto arquitectónico.

Bloque temático: espacio público y proyecto urbano en la metrópolis contemporánea.

\section{ABSTRACT}

Contemporary art centers are considered urban transformation engines, which has been observed in many cities around the world. Therefore, the objective of this article is to analyze the Centro Nacional de Arte Contemporáneo Cerrillos, the only one of its kind in Chile. To this end, a multidisciplinary methodological and multi-method strategy is deployed that allows the study of an institutional case. As a result, the center is described according to four dimensions: historical, urban, architectural and sociocultural. In the discussion, connectivity, accessibility, readability, tours and permanence and flexibility are analyzed. It is concluded that, although it is necessary to promote some secondary elements, this center operates as an engine of transformation of a devalued sector of the city.

Keywords: Contemporary art center, transformation engine, contemporary art, urban project, architectural project.

Topic: public space and urban project in the contemporary metropolis.

${ }^{1}$ Ponencia basada en el artículo: Gallardo Frías, L., Toledo Jofré, M., Figueroa Garavagno, C., Vera Bravo, J., \& Pérez Huenupi, L. (2019). Centro Nacional Arte Contemporáneo Cerrillos (CNACC): motor de transformación de la ciudad de Santiago. Revista de Urbanismo, (40). doi:10.5354/0717-5051.2019.52362. Esta ponencia forma parte del proyecto de investigación FONDECYT No 11170140 financiado por el Fondo Nacional de Desarrollo Científico y Tecnológico de Chile. 


\section{Introducción}

Durante los últimos tiempos, los museos y centros de arte contemporáneo han funcionado como motor de transformación en numerosas ciudades del mundo, siendo capaces de rehabilitar y reestructurar áreas urbanas (Layuno, 2003). Existen numerosos ejemplos internacionales sobre cómo estos centros han impulsado sectores de la ciudad, en los cuales el vínculo con sus habitantes ha sido un factor clave para la regeneración de barrios. El Centro Georges Pompidou de París (1977), constituye un motor de regeneración cultural que anula las fronteras entre arte y vida cotidiana (Zunzunegui, 1990). A partir de este hito, los museos y centros de arte se conciben como una continuidad entre interior y exterior, y el espacio museístico se expande hacia una plaza abierta a numerosas actividades, conectándose con su comunidad (Layuno, 2003). En la misma línea, es decir, con el fin de atraer la atención de sus ciudadanos, generar un hito urbano e incentivar la actividad económica y política, surge el Guggenheim de Bilbao (1997). Su impacto es de tal magnitud que el Efecto Guggenheim (Esteban, 2007) se replica en otras ciudades para regenerar sectores industriales como el caso de la Fundación Dia Center for the Arts en Nueva York y la reapertura del Museo de Antioquia de Medellín, Colombia.

En el plano nacional, una reciente investigación concluye que "los museos de arte pueden operar como mecanismos de inclusión social en el sistema funcional de arte y en la sociedad..." (Valenzuela et al. 2015: 734), lo que confirma el rol que puede tener la constitución de un centro de arte contemporáneo en áreas desvalorizadas de la ciudad. Sin embargo, en Chile no se han realizado investigaciones que se enfoquen específicamente en este tema, ya que la mayoría de ellas se han realizado "bajo el enfoque de 'consumo cultural'. Esta perspectiva reduce la mirada sobre el acercamiento al arte visual que también se puede analizar desde otros enfoques. Por ejemplo, aquellas que consideran que una obra de arte involucra diversas formas de 'sentir-pensar-saber' que no necesariamente son inmediatas" (Consejo Nacional Cultura y las Artes, s.f: 27). Por ello, sería relevante que las investigaciones consideren la relación entre visitantes, centros y arte.

El objetivo de este artículo es analizar un centro de arte contemporáneo en tanto motor de transformación de la ciudad. Por ello, se estudia el Centro Nacional de Arte Contemporáneo Cerrillos (CNACC), único en su tipo, que, además, se ubica fuera de la zona de concentración de instituciones culturales de Santiago.

\section{Metodología.}

El tipo de investigación es el estudio de caso único, es decir, un corpus empírico que se representa en singular, específicamente, un caso institucional. Se estudia en profundidad porque permite aprender de su análisis y puede contribuir de manera significativa a la producción de conocimiento, siendo a la vez una vía de acceso a otros fenómenos o aspectos del caso (Pires, 1997). Para el estudio se consideran cuatro dimensiones que permitirían analizar el poder transformador del centro: dimensión histórica que busca revisar los procesos pasados acaecidos en el sector que persisten en las memorias y posibilitan imaginar el futuro; dimensión urbana que examina la relación entre el CNACC con la ciudad, la comuna y el barrio, así como su conectividad y relaciones con espacios verdes, e hitos urbanos; dimensión arquitectónica que describe el funcionamiento del centro de arte, sus accesos, circulaciones y relaciones espaciales; y dimensión sociocultural que describe la experiencia de visita de los habitantes.

Como metodología se despliega una estrategia multidisciplinaria y multi-método que permite producir conocimiento para cada una y todas las dimensiones analizadas. Para la recolección de la información se construye una matriz de análisis de datos (Miles, Huberman \& Saldaña, 2014). En ella se identifican las dimensiones y sus indicadores. Esta matriz permite cruzar la dimensión histórica, urbana y arquitectónica con la sociocultural. Para recolectar la información se aplican metodologías específicas. En la dimensión histórica se recopilan y analizan documentos históricos, material bibliográfico e información secundaria. En la dimensión urbana se realiza un estudio planimétrico en tres escalas: ciudad, comuna y barrio, con superposición de capas de información. En la arquitectónica se trabaja una planimetría de base que se estructura en una secuencia 
desde el exterior hacia el interior. En la dimensión sociocultural se realiza un trabajo de tipo etnográfico que incluye observación participante y entrevistas. La información recolectada es vaciada en la matriz.

\section{Análisis del centro nacional de arte contemporáneo cerrillos}

\subsection{Dimensión histórica}

Las obras del primer aeropuerto de Chile, a cargo de los arquitectos del Ministerio de Obras Públicas: Jorge Ugarte, Eduardo Arrau y Juan Mena, comenzaron en 1929. Esta obra fue parte del plan modernizador del Estado, impulsado por el gobierno de Ibáñez del Campo, que creó numerosas instituciones. El dinero para la construcción del aeropuerto fue donado por Daniel Guggenheim, miembro de una de las familias más ricas de EE. UU. que, desde principios de siglo, mantenía capitales en la minería en Chile y otras partes del mundo. Esta inyección financiera se enmarcó en la creciente llegada de capitales norteamericanos en forma de créditos, inversiones y donaciones que desplazaron a las inversiones europeas (Rinke, 2013).

Sin embargo, en 1931, los efectos de la Gran Depresión, la paralización de los distintos sectores de la economía, la caída del gobierno de Ibáñez y la fuerte agitación revolucionaria, obligó a la paralización de las obras. Estas solo fueron retomadas en el año 1933, bajo el segundo gobierno de Alessandri Palma quien impulsó un amplio plan de obras públicas tendiente a revertir los graves niveles de cesantía en el país (Correa, et.al., 2001). El edificio fue finalmente inaugurado en 1934.

En 1957 se efectuó una remodelación del edificio terminal, siguiendo el diseño propuesto por la arquitecta Iris Valenzuela, del Ministerio de Obras Públicas, que, a partir de la incorporación del Mural de los Cóndores, obra de Samuel Román Rojas y su hijo Héctor Román Latorre, eliminó las curvas de la fachada norte. Este último Héctor Román- también fue el autor del mural que se ubica en el interior del edificio. Ambos murales persisten hasta hoy. Además, se amplió la pista de aterrizaje que llegaría a 2.342 metros de largo (Eliash, 2013: 5). Sin embargo, el crecimiento urbano de Santiago imposibilitó la extensión de su pista de aterrizaje.

Es por esta razón que en 1961, durante el segundo gobierno de Carlos Ibáñez del Campo, empezó a construirse el Aeropuerto de Pudahuel, inaugurado en febrero de 1967. Desde esa fecha hasta el 2006 Cerrillos siguió funcionando como aeródromo para viajes de cabotaje interno, algunos vuelos de la FACH y de las escuelas de aviación. Paulatinamente fue ocupando un lugar secundario en las comunicaciones aéreas nacionales. Las líneas aéreas LAN Chile y LADECO dejaron de utilizar este recinto en 1975 y 1981 respectivamente (Eliash, 2013: 5). Pese a que desde 1992 hasta su cierre tuvo lugar allí la Feria Internacional del Aire y del Espacio (FIDAE), esta no logró revitalizar el aeródromo. En 2006 la FACH trasladó su base aérea a El Bosque y traspasó los terrenos del aeropuerto al Servicio de Vivienda y Urbanismo (SERVIU) Metropolitano, lo que llevó al cierre definitivo del terminal aéreo. En 2016, la presidenta Bachelet anunció la creación del Centro de Arte Contemporáneo Cerrillos, que fue inaugurado en septiembre de ese mismo año. 

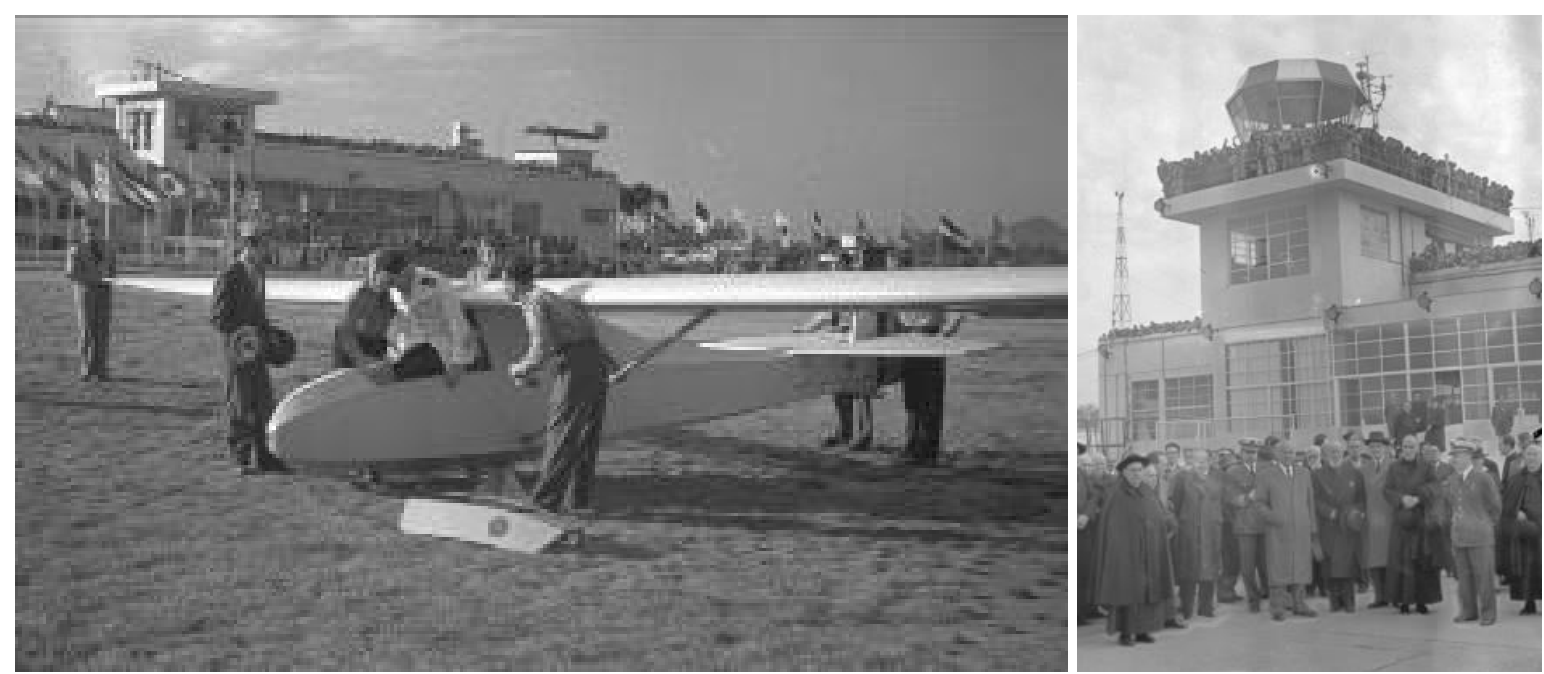

Figs. 1. Izquierda: Recibimiento Cardenal José María Caro. Fuente: Copyright@ "Colección Museo Histórico Nacional". Autor: Miguel Rubio Feliz. Derecha: Recibimiento Cardenal José María Caro, 1946. Fuente: Copyright@ "Colección Museo Histórico Nacional". Autor: Miguel Rubio Feliz.

En 1981, la dictadura liderada por Augusto Pinochet creó 17 comunas nuevas, siguiendo lógicas políticas "despolitizadoras" con el fin de fortalecer la centralización a partir de la fragmentación de los espacios nacionales, regionales y comunales (Valdivia, 2015), de modo de controlar la subversión y delimitar los focos de pobreza. Una de ellas fue Cerrillos. No obstante, la vigencia de este Decreto con Fuerza de Ley, la comuna no se instaló como tal sino hasta el año 1991, momento en que fue designado el primer alcalde comunal.

En 2008 el Ministerio de Vivienda y Urbanismo abrió un concurso para el diseño y construcción de la Ciudad Parque Bicentenario en los terrenos del aeródromo Cerrillos. El objetivo del Plan Maestro era propender "a la generación de condiciones urbanas apropiadas para la consolidación del proceso de reconversión de los vacíos interiores urbanos [...] desde la perspectiva de un desarrollo urbano integrador, integral y amable con su medio ambiente" (Galilea, 2006: 58). El equipo liderado por el arquitecto Humberto Eliash se adjudicó el diseño.

La apertura del CNACC en 2016 significó, en palabras del entonces Ministro de Cultura Ernesto Ottone "la recuperación de un espacio para un proyecto inédito, impulsado plenamente por el Estado y desde el cual se desarrollará de manera integral el trabajo en torno a las políticas públicas, investigación, experimentación y al mismo tiempo exhibición y mediación del arte contemporáneo, en una comuna que se levanta como futuro polo cultural para Santiago y todo el país" (Ministerio de las Culturas, las Artes y el Patrimonio, 2016, ๆ 6). Según se explicita en el catálogo de la exposición con que se inauguró el centro, titulado Una imagen llamada palabra, este tiene por misión “... promover y estimular la creación, experimentación, reflexión y comprensión del arte contemporáneo chileno, en conexión con la escena latinoamericana, poniendo a disposición de la ciudadanía las herramientas para su conservación, investigación, educación y difusión." (CNACC, 2016: 8).

\subsection{Dimensión urbana.}

En Santiago de Chile las obras arquitectónicas destinadas al arte -museos, centros culturales y galerías- se encuentran concentradas en el sector centro-oriente de la ciudad, dejando al resto de las comunas desprovistas de lugares para el arte, como se puede observar en el plano de emplazamiento del CNACC (fig. 2, izquierda). En este sentido, la apertura del centro en la Comuna de Cerrillos, al Sur Poniente de Santiago, constituye una excepción.

Según el Plan de Desarrollo Comunal (PLADECO, 2011), una de las principales características de esta comuna es la gran cantidad de viviendas sociales, en un sector con baja densidad de población. Su carácter es más bien industrial. La 'visión' de este Plan indica que "Cerrillos es una comuna residencial, industrial y comercial 
que se proyecta y consolidará como un Subcentro Metropolitano de servicios, a escala humana, sustentable y moderno." (PLADECO, 2011: 88)

Una de las principales características de esta comuna es la existencia de gran cantidad de viviendas sociales en un sector industrial. Según la Ilustre Municipalidad "Cerrillos es una comuna residencial, industrial y comercial que se proyecta y consolidará como un Subcentro Metropolitano de servicios, a escala humana, sustentable y moderno." (Ilustre Municipalidad de Cerrillos, 2011: 88).

Las vías principales de conexión del CNACC con la ciudad son, como se muestra en el plano (fig. 2, derecha): Av. Pedro Aguirre Cerda, Américo Vespucio, Av. Lo Errázuriz y Av. Departamental, las que permiten conectar también los principales hitos urbanos de la comuna.

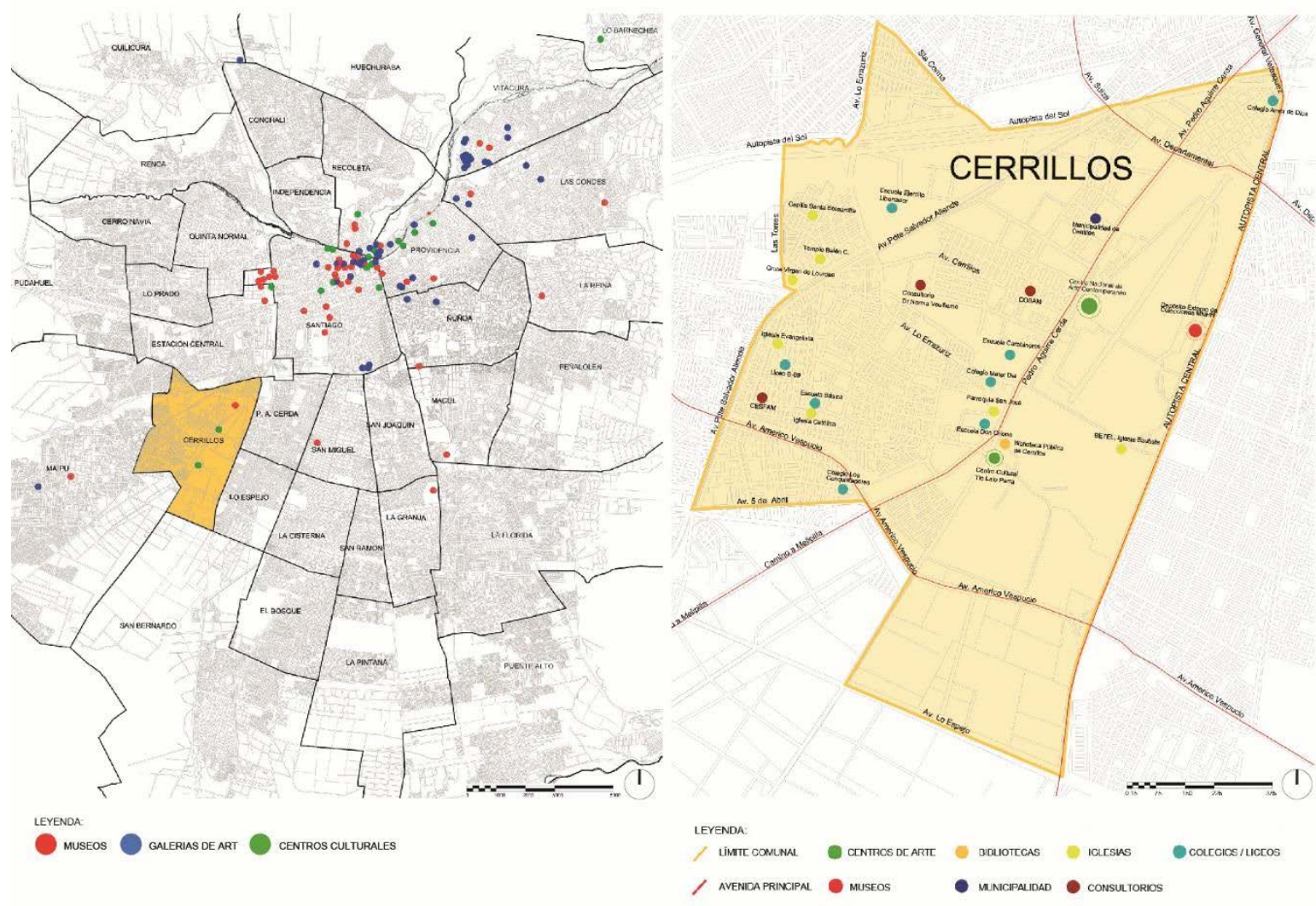

Figs. 2. Emplazamiento del CNACC. Izquierda: CNACC en relación a la ciudad y obras arquitectónicas destinadas al arte. Derecha: CNACC comuna Cerrillos. Fuentes: Elaboración propia en base a Plano Comunal Santiago www.sitio.cartografia.cl

Alrededor del CNACC existen numerosos terrenos baldíos (fig. 3) producto del cono de aproximación al exaeropuerto, susceptibles de ser urbanizados y constituir otro polo para la ciudad de Santiago, favorecido por la reciente apertura de la línea 6 del metro (2017) con la parada de Cerrillos, las conexiones a grandes vías de comunicación y la ciclovía. En el sector se emplazan también el Museo Aeronáutico, el Centro Cultural Lalo Parra, la Biblioteca Pública de Cerrillos y próximamente se abrirá una sede del Museo de Historia Natural. Además de estos hitos urbanos, destaca la proximidad y conexión con el parque Portal Bicentenario, de 50 hectáreas, que se traza, según indican sus autores, "a partir de la pista de aterrizaje existente como elemento organizador con un sistema de parques transversales y vías parque que complementan la función del parque central y ligan los distintos distritos del proyecto constituyendo una imagen de 'ciudad parque'. ... El parque central es una pieza clave y su diseño responde tanto a la voluntad de construir una imagen reconocible con relación al eje definido por la pista aeronáutica y su posible proyección hasta el anillo de circunvalación Américo 
Vespucio, como a la necesidad de su uso cotidiano como corazón del proyecto, lugar de encuentro y de paso para sus habitantes y los del entorno" (Lobos \& Montealegre, 2007: 2).

Este parque recoge solo algunos aspectos del proyecto inicial de Ciudad del Viento, basado en la idea de una ciudad sustentable, que ganó el Concurso Internacional de Ideas organizado en 2001 por Ministerio de Vivienda y Urbanismo (MINVU) en conjunto con el Colegio de Arquitectos de Chile (Eliash, 2006) con la finalidad de seleccionar un diseño que propusiera al aeródromo como centro de un proyecto urbano (González, 2010).

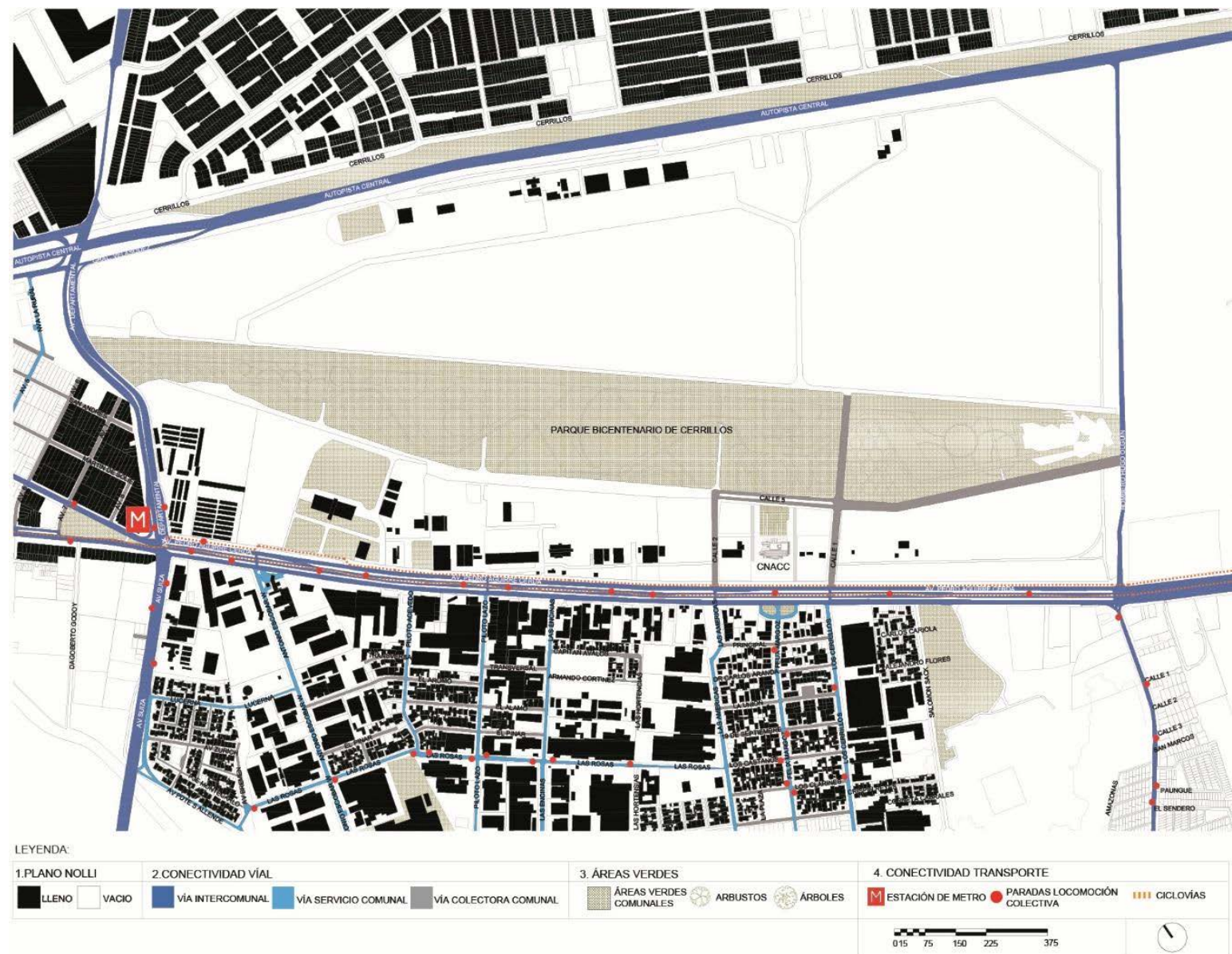

Fig.3. Plano emplazamiento CNACC. Fuentes: Elaboración propia, basado en planos entregados por CNACC, corroborados en terreno y Google Earth

EI CNACC constituye un hito urbano, ya que articula el proyecto de gestión urbana Ciudad Parque Bicentenario (CPB), dirigido por el Ministerio de Vivienda y Urbanismo. Este último aspira albergar, en 20 años, a unas 16.500 familias. Los lineamientos estratégicos del CPB se definieron en base al Plan Maestro de Ciudad Parque Bicentenario, desarrollado entre los años 2003-2005 por el consorcio Asociación Portal Bicentenario liderado por URBE arquitectos, a partir de tres criterios urbanos (González, 2010):

1) Zonificación base: articula el proyecto en torno al parque central Bicentenario con distintas franjas de usos y densidades (Fig. 4); 


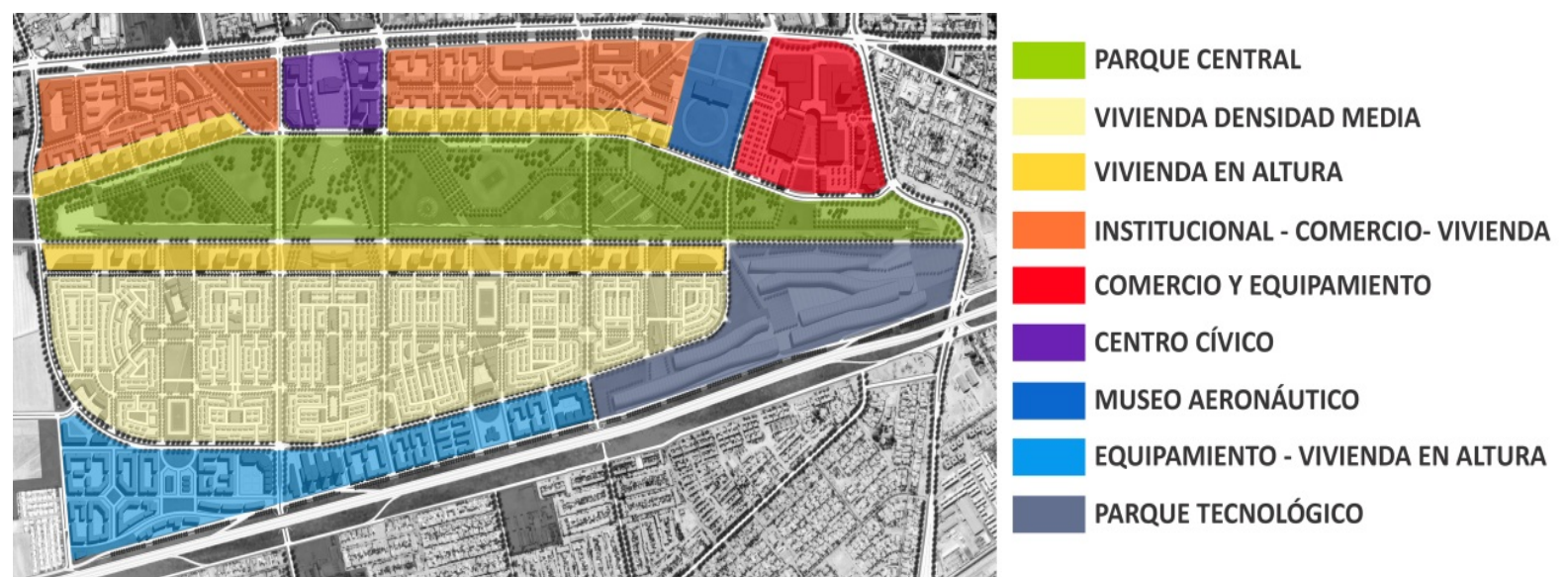

Fig.4. Detalle del Plan Maestro de Ciudad Parque Bicentenario. Ministerio de Vivienda y Urbanismo.

2) Generación de conectividad: a través de vías que estructuran el conjunto y permiten conectar con las comunas colindantes (fig. 5);

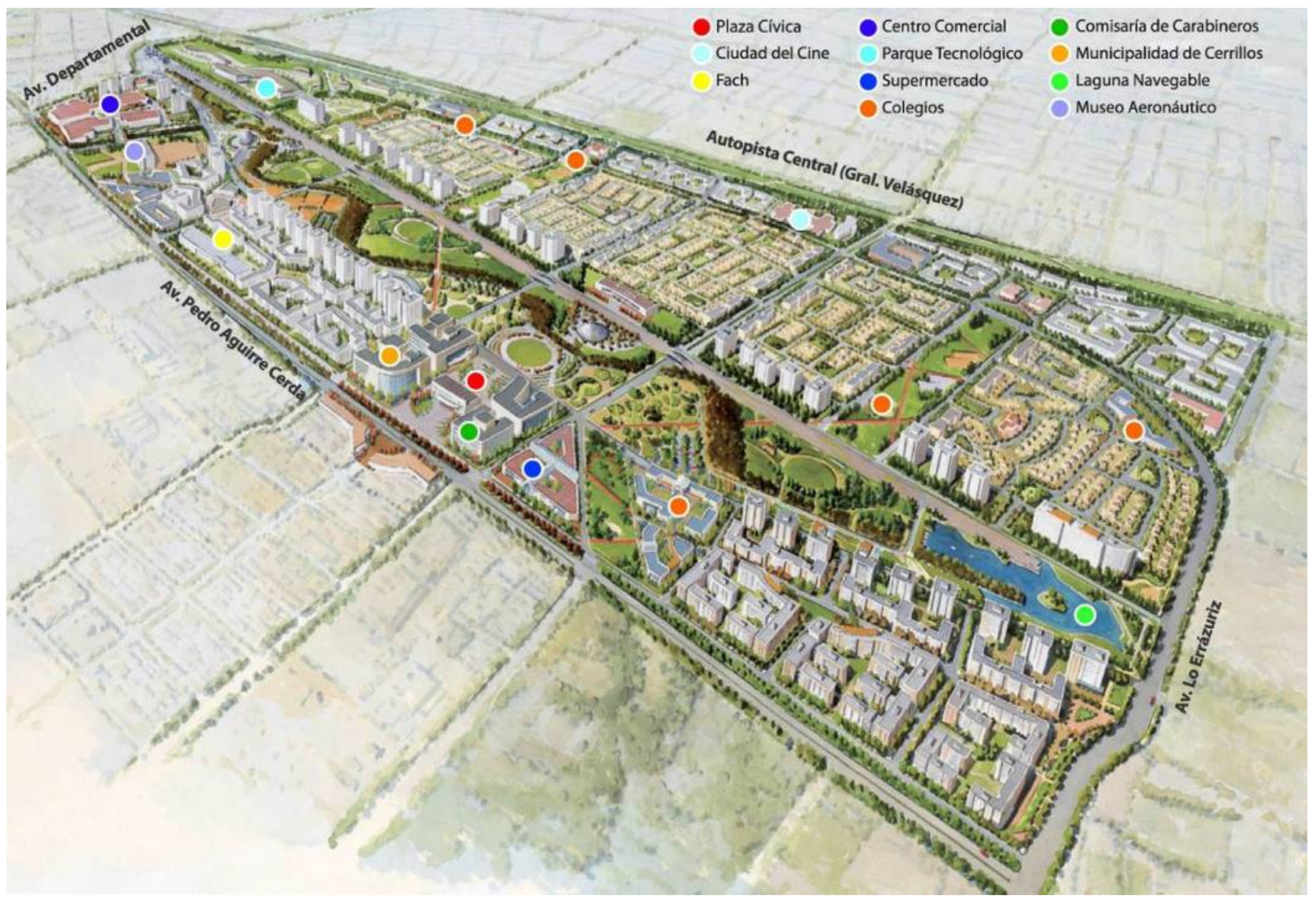

Fig. 5. Vista del proyecto Ciudad Parque Bicentenario. Ministerio de Vivienda y Urbanismo.

3) Valorización de lo existente: construcción de un centro cívico localizado en la zona donde se ubica el actual CNACC, en conexión con el Museo Aeronáutico y el Centro Cultural Lalo Parra. Según Lynch, la torre de control y las características arquitectónicas de la edificación, la constituirían en un hito urbano "fácilmente identificable" (2006: 11). 


\subsection{Dimensión arquitectónica}

La actual edificación del CNACC ha sido sometida a distintas transformaciones (fig. 6).

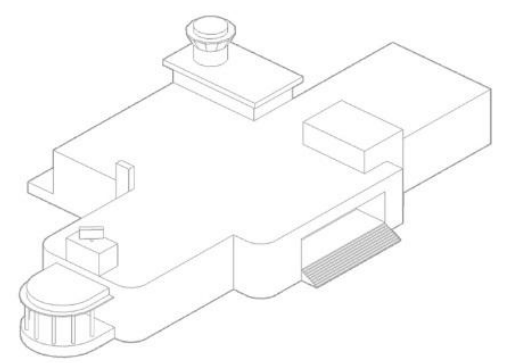

AXONOMETRICA VOLUMEN EDIFICIO ORIGINAL FECHA: 1933

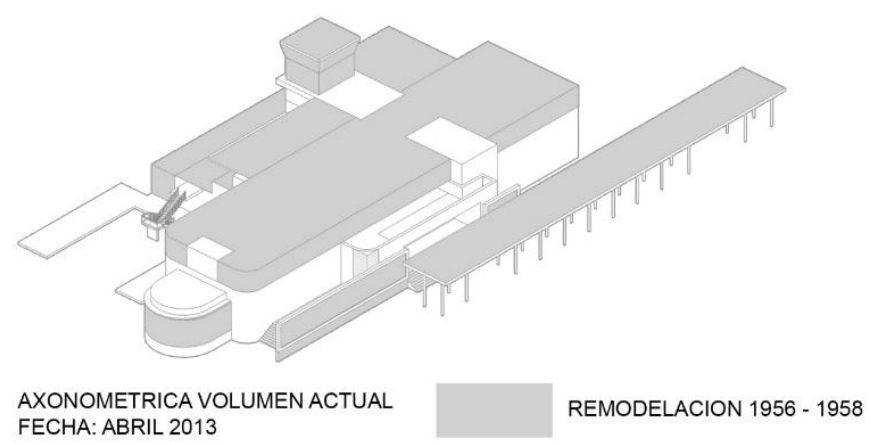
FECHA: ABRIL 2013

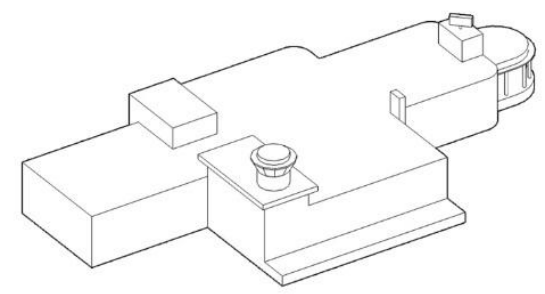

AXONOMETRICA VOLUMEN EDIFICIO ORIGINAL FECHA: 1933

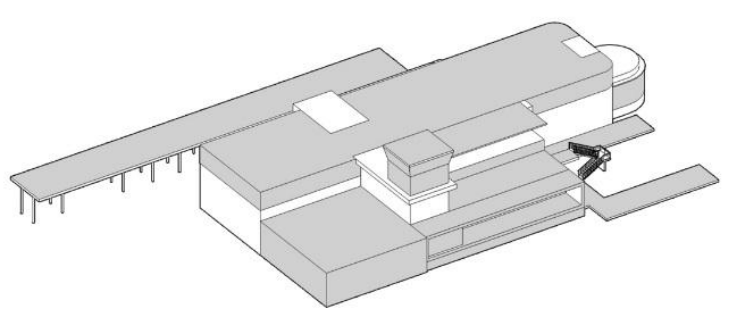

AXONOMETRICA VOLUMEN ACTUAL FECHA: ABRIL 2013

REMODELACION 1956 - 1958

Figs. 5. Axonométricas del aeropuerto de Cerrillos y remodelaciones hasta el actual CNACC. Fuente: Eliash, 2013.

El acceso al CNACC se realiza por dos sectores. Uno de ellos es por Av. Pedro Aguirre Cerda. Como se aprecia en la imagen (fig. 7 izquierda) allí existe una valla que divide el terreno del centro con la vereda, la cual -según señala su directora, Beatriz Salinas, en entrevista (29 junio 2018)- están intentado eliminar. Desde este acceso, la antigua torre de control es poco reconocible a nivel de calle debido a la incorporación de la tercera planta en la última remodelación del ex - aeropuerto. Lo mismo ocurre con las letras situadas en el acceso principal que, desde la vereda, son poco visibles. La valla y la escasa visibilidad dificultan el acercamiento de la comunidad a la edificación, a pesar de contar con una gran explanada de antesala. El otro acceso es por el parque Portal Bicentenario de Cerrillos. Desde allí sí es visible la ex - torre de control que, junto con las franjas de pavimento que conectan con el parque, invitan a acercarse al Centro de Arte como se observa en la imagen (fig. 7 derecha). Ambas entradas cuentan con acceso universal. 

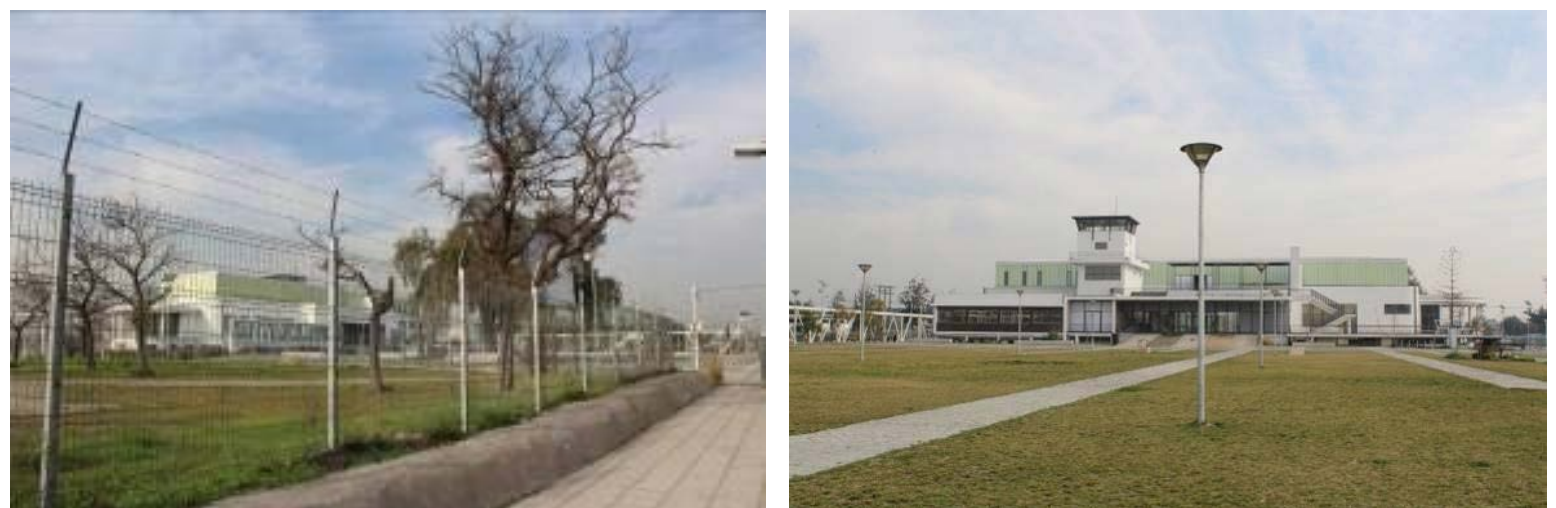

Figs. 7. Izquierda: Imagen del acceso por la vereda de Av. Pedro Aguirre Cerda. Derecha: Acceso por el parque Portal Bicentenario Fuente: Elaboración propia.

Al interior del Centro, en la planta +1 nivel de calle, se sitúa un hall central que conecta ambos accesos y que, en ocasiones, se utiliza como soporte de obras de exhibición. En este mismo nivel se encuentran distintas salas de exposiciones, el Centro de Documentación de Artes Visuales (CEDOC), la sala de exposición experimental y los baños de mujeres, como se muestra en el plano (fig. 8, primera).

En el nivel -1, se sitúa una sala de exposiciones alrededor del núcleo del ascensor. Este piso cuenta con un acceso independiente para la llegada de las obras, además de bodegas, depósitos de obras, taller pañol y salas de cuarentena para el proceso de exposición. También se sitúan los talleres de mediación, baños de hombres, baño universal, sala multiuso y una sala de exposición permanente, además de los baños y cocina del personal (fig. 8, segunda). En el nivel +2 se encuentra la sala de exposición principal, con una pequeña bodega. En el sector este y oeste están las oficinas, junto con unas amplias terrazas hacia la cordillera de los Andes, como se muestra en el plano (fig. 8, tercera). En el nivel +3 , en la antigua torre de control se encuentra una sala de usos múltiples con vista hacia la cordillera, como se observa en el plano (fig. 8, cuarta).

A pesar de que la edificación original fue un aeropuerto, los espacios servidores y servidos en el CNACC, se diferencian con claridad. Sin embargo, existen demasiados núcleos de escaleras en relación a la superficie de la planta, como se muestra en el siguiente análisis planimétrico (figs. 8). 


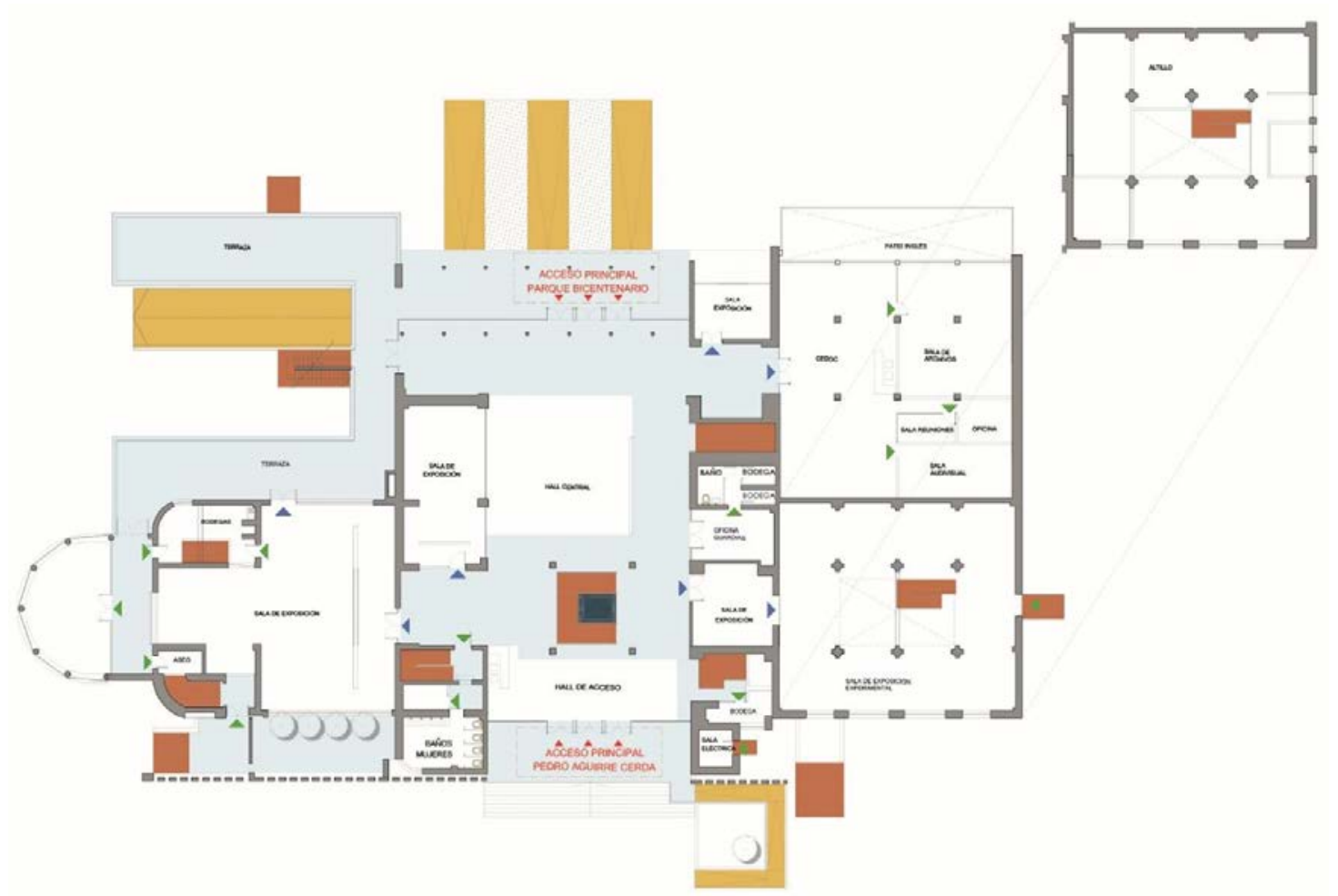

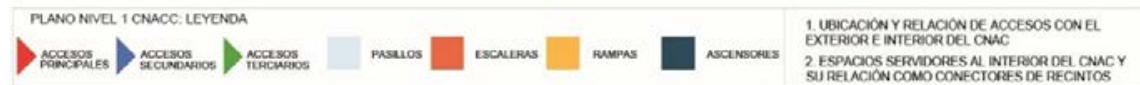

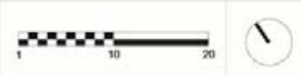

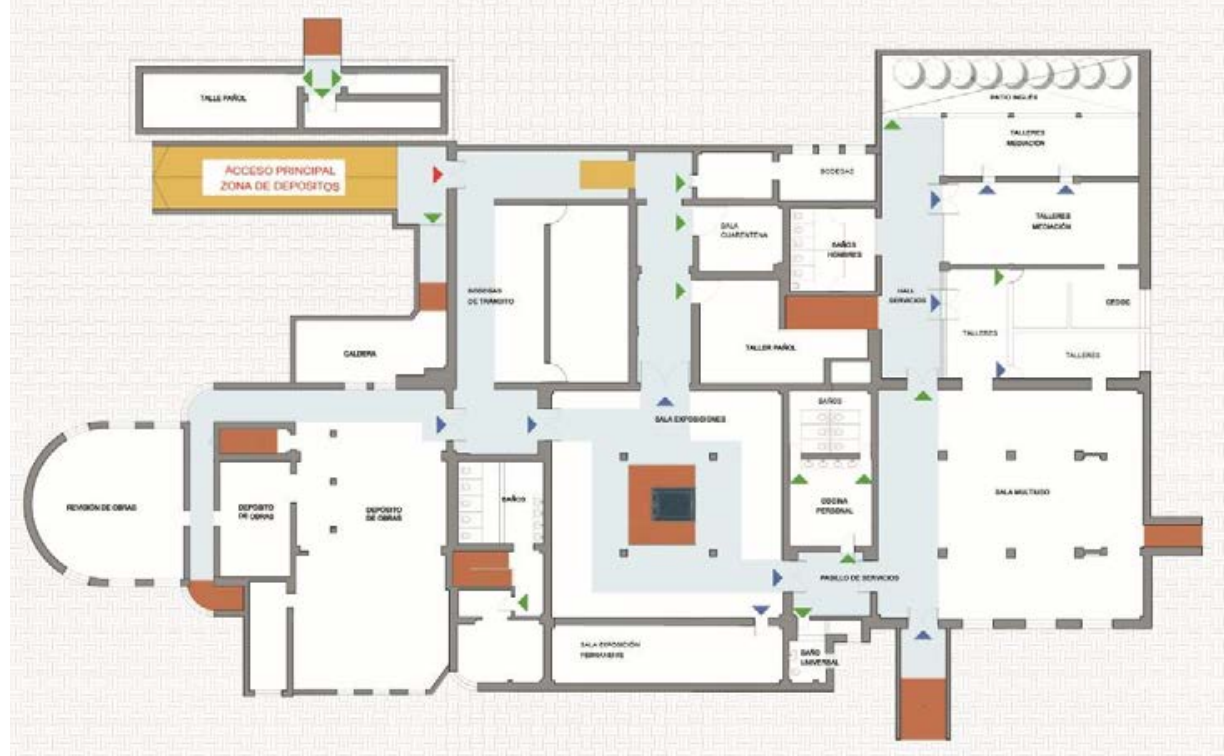

PLANO NIVEL - I CNACC: LEYENDA

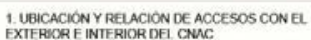

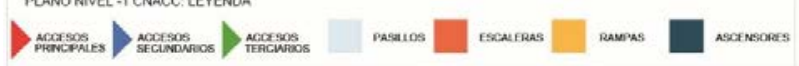



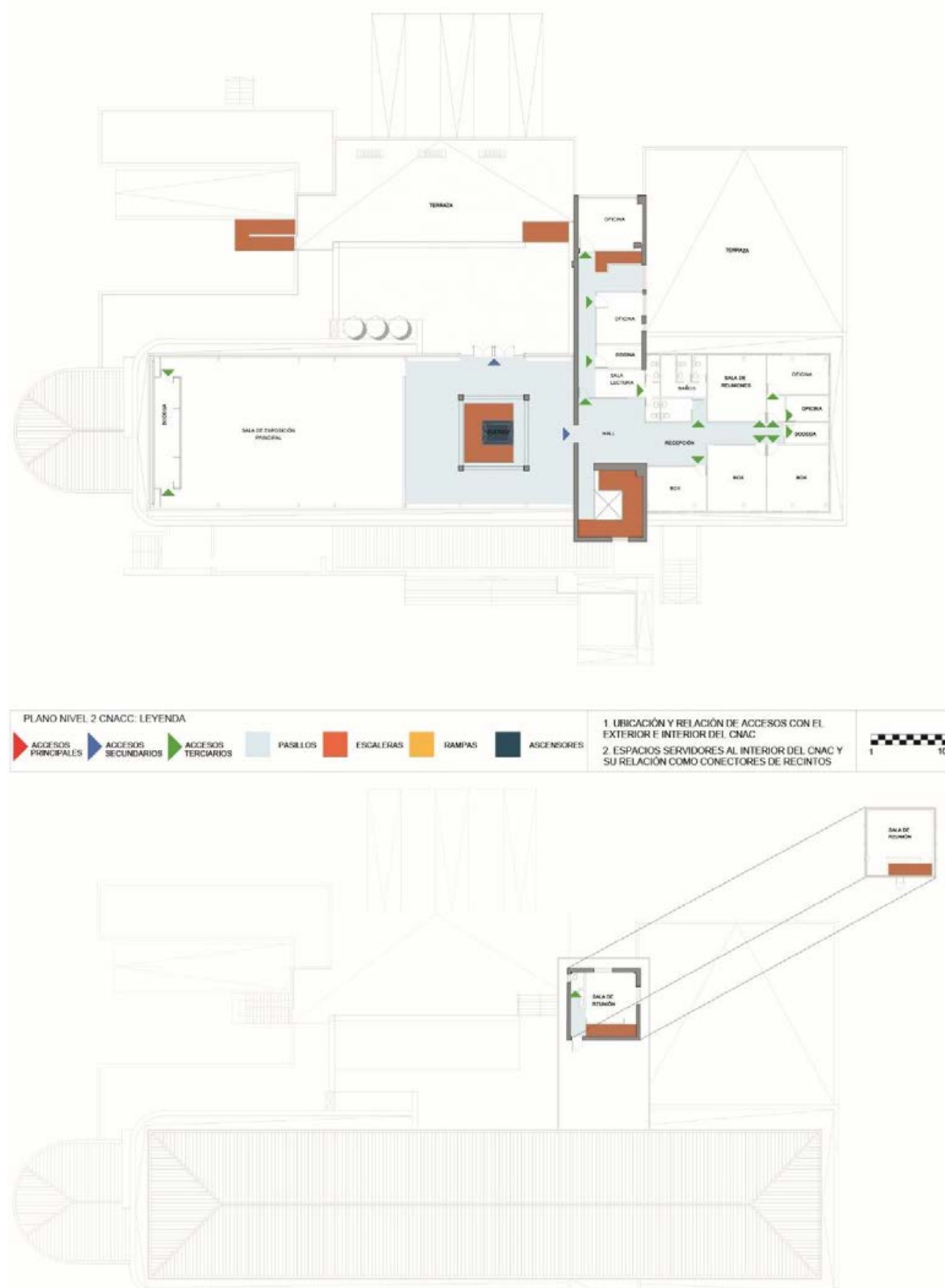

PLANO NIVEL 3 CNACC: LEYENOA

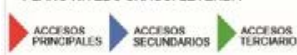

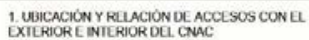

2ESPACIOS SERVIDORESAL INIERSOR DEL CNACY Y
SU RELACION COMO CONECTORFS OE RECINTOS

Figs. 8. Planimetrías CNACC: recintos, análisis de accesos y espacios servidores y servidos.

Fig. 8. Primera: Plano nivel 1 CNACC. Fig. 8. Segunda: Plano nivel -1 CNACC. Fig. 8. Tercera: Plano nivel +2 CNACC. Fig. 8. Cuarta: Plano nivel +3 CNACC. Fuente: Elaboración propia, basado en planos entregados por CNACC, corroborados en terreno. 
Las alturas entre losas, que oscilan entre los 2,90 metros en la planta -1, 4 metros en el hall principal y 3,70 metros en la sala de exposición principal del nivel +2 (fig. 9), hacen posible la exhibición de distintas exposiciones. Además, la entrada de luz natural desde el exterior permite una buena iluminación en las salas principales.

La edificación mantiene las fachadas originales (figs. 9), su volumen circular, el mural y la antigua torre de control, que dialogan con la ampliación del segundo piso, produciendo un encuentro de volumetrías, colores y materiales.
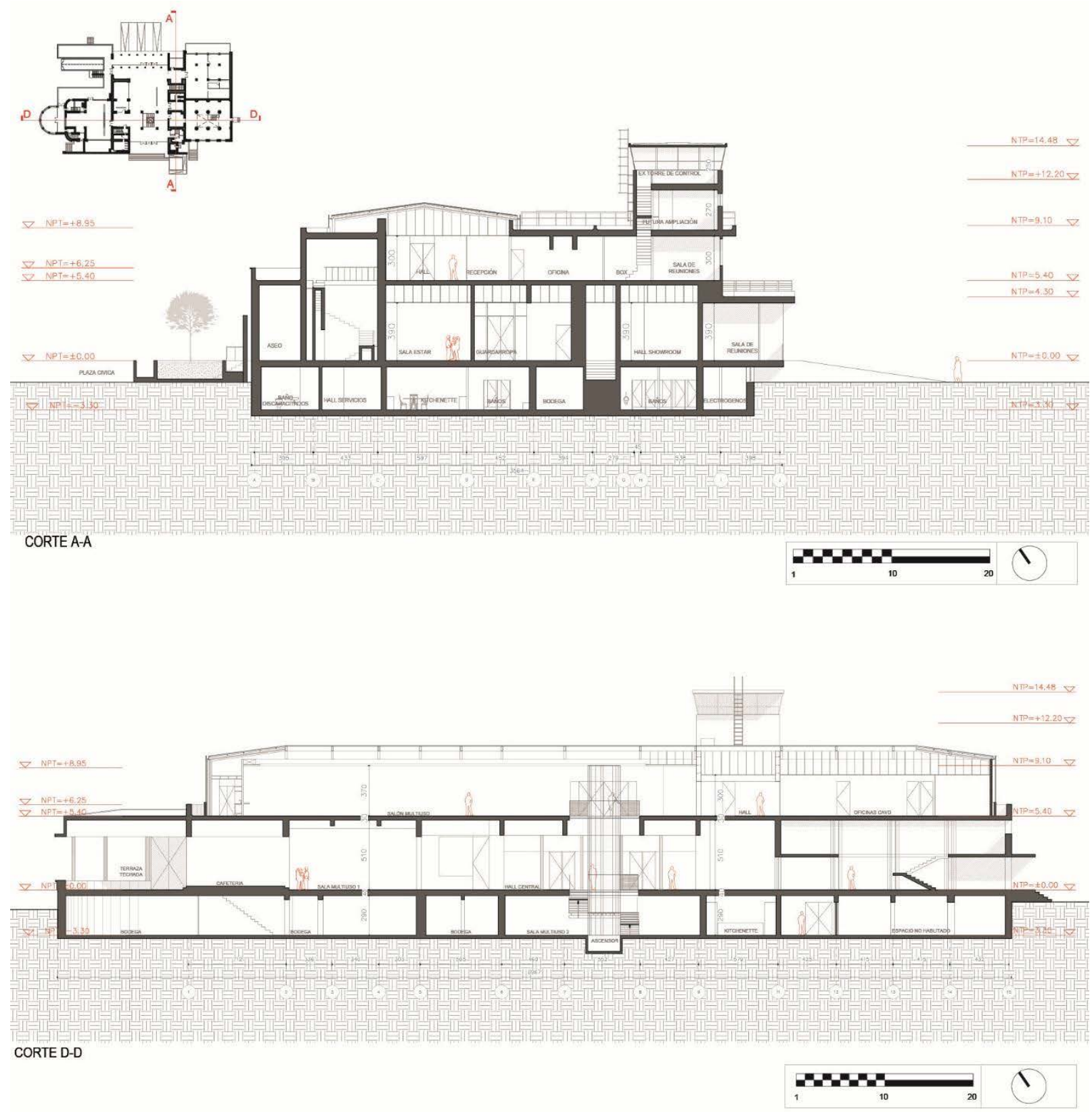

Fig. 9. Cortes del CNACC. Fuente: Elaboración propia, basado en planos entregados por CNACC, corroborados en terreno 


\subsection{Dimensión sociocultural}

El personal que trabaja en el Centro Nacional de Arte Contemporáneo Cerrillos se ocupa de las áreas de exposición, investigación y mediación. La mayoría de ellos -directora, mediadores y funcionarios- se ubica en las oficinas del piso +2 . En la planta +1 trabaja el personal del Centro de Documentación de Artes Visuales (CEDOC) y la recepcionista que resuelve las inquietudes de los visitantes. Al interior del Centro circulan trabajadores de empresas externas que prestan servicios de vigilancia y aseo. En las plazas de acceso trabajan funcionarios de la llustre Municipalidad de Cerrillos que se ocupan de la mantención de las áreas verdes.

Hay personas que transitan por el sector e ingresan, pero, la mayoría de los visitantes provienen de otras comunas, particularmente de la zona oriente de Santiago, aunque otros residen o trabajan en Cerrillos. Tienen distintas edades y niveles educacionales. Acuden solos, en parejas, en familia o en grupos de estudiantes con sus profesores. Entre los visitantes se cuentan quienes ingresan a ver las exposiciones y quienes participan en actividades de mediación que organiza el CNACC. Estas están dirigidas especialmente a niños y vecinos adultos mayores. Cuando se trata de niños, van acompañados de un adulto. También hay quienes acuden directamente al CEDOC a consultar los archivos de arte. Este último es un público especializado: profesionales, investigadores, artistas, curadores y estudiantes.

Los visitantes y los trabajadores consideran que el CNACC no es muy conocido debido a la falta de difusión. Los primeros cuentan que acuden a las exposiciones porque se han informado de boca en boca, pero luego de tener conocimiento de las actividades, algunos buscan más información en la página Web institucional. También hay visitantes que reportan haberse informado de las exposiciones por medio de la radio, la televisión y las redes sociales.

Mientras que los visitantes que viven en la comuna llegan caminando, quienes vienen desde comunas lejanas planifican su viaje. Estos últimos utilizan diferentes medios de transporte como automóvil, buses de locomoción colectiva, metro o bicicleta. La conectividad es bien valorada y la existencia de la nueva estación de metro, facilita el acceso.

Aunque en el imaginario de los visitantes de comunas lejanas el centro se encuentra en un lugar apartado de la ciudad y de difícil acceso, luego de su visita, este se modifica. Un residente de la Comuna de Ñuñoa comenta “... pensé que era difícil llegar, pero no era complicado." (Entrevista $\left.N^{\circ} 13\right)$. Otra visitante que habita en el centro de la ciudad lo confirma, señalando: "Pensé que era más complicado." (Entrevista Nº12). Sin embargo, en la estación de metro más cercana no hay señalización alguna que informe sobre la ruta hacia el CNACC. Nada indica tampoco que es posible tomar un bus para recorrer el kilómetro y medio que lo separa de la estación.

EI CNACC se ubica, según los visitantes, en un sector de la ciudad lejos del lugar de residencia de los grupos económica y culturalmente privilegiados. Por ello, un visitante de la zona oriente de Santiago dice: "El problema es que queda muy alejado." (Entrevista $\left.N^{\circ} 25\right)$. Sin embargo, otro residente del mismo sector explica: "Para nosotros era lejos... Pero, en Santiago todo es lejos. Así que, da lo mismo donde uno tenga que ir." (Entrevista $\mathrm{N}^{\circ} 7$ ). Los habitantes del sector oriente de la capital valoran que el nuevo centro haya sido inaugurado en el sector poniente, donde antes no se tenía acceso al arte.

Dado que el centro se emplaza en una zona industrial, por las calles aledañas no abundan los transeúntes que, sin mediar planificación, puedan decir: "... voy a entrar al museo." (Entrevista №14). Además, al estar emplazado sobre un gran espacio vacío, un visitante que habita una comuna lejana, explica "... vimos lo bonito que estaba la Cordillera de los Andes." (Entrevistado $\mathrm{N}^{\circ} 6$ ).

Cuando los adultos mayores visitan el CNACC surgen los recuerdos. Una visitante cuenta: "Yo vine al aeropuerto... Entonces, uno tiene una remembranza.... Veías a la gente que estaba encima del avión... Yo vine. No me subí al avión aquí. ... Pero vine a buscar y a dejar personas al aeropuerto." (Entrevista №25). Y 
un guardia del centro explica: "Yo también conocí el aeropuerto. Pero nunca había entrado. ... A mí me encanta, porque soy de la época en que esto era aeropuerto... Veías despegar y aterrizar aviones..." (Entrevista №23).

Para los visitantes que no conocían el aeropuerto, "... arquitectónicamente, es un edificio bastante tosco para ser un museo de arte. ... Este parece más un edificio convencional... Parece más un estacionamiento." (Entrevista $\mathrm{N}^{\circ} 15$ ). Los visitantes de otras comunas piensan que debería haber señalética que informen la existencia del centro. Esto porque desde fuera el CNACC “... no invita a entrar. Faltan más anuncios o algo que te indique que es un museo." (Entrevista $\left.N^{\circ} 15\right)$. Además, explican los visitantes, la reja que se ubica a lo largo del frontis no permite visualizar el acceso, ni menos saber si está abierto o cerrado.

La fachada, según una visitante que habita en una comuna cercana, “... parece como la típica empresa... Yo, le hubiese puesto un poco más entretenido o más innovador... Como algo que te invite a entrar, que te diga: 'aquí tenemos cosas para aprender, para conocer'... Si tú lo miras así, parece hasta un hospital." (Entrevista $N^{\circ} 5$ ). También indican que las letras que informan el nombre del CNACC son muy pequeñas y no se ven.

En la plaza posterior, durante los fines de semana de la exposición Algoritmos del Viento, se instalaron Food Trucks y pequeños quitasoles para que los visitantes pudieran permanecer sobre el pasto. Ahí también se pusieron en movimiento algunas de las obras de Theo Jansen. Durante esos días, los numerosos visitantes también usaron los bancos ubicados bajo los corredores techados para protegerse del sol, descansar y consumir refrigerios.

Los visitantes ingresan al edificio por uno de sus dos accesos: por la puerta principal, suelen entrar quienes llegan por medio del transporte público y, por la parte posterior, quienes se trasladan en automóvil o caminan desde el Parque Bicentenario. Los visitantes consideran que las salas son adecuadas y que el espacio interior es amplio. (figuras 10).

Cuando el acceso al público no está controlado, los visitantes circulan libremente al interior del centro. No hay señalética que indique la ubicación de las salas y las obras exhibidas que no están a simple vista.

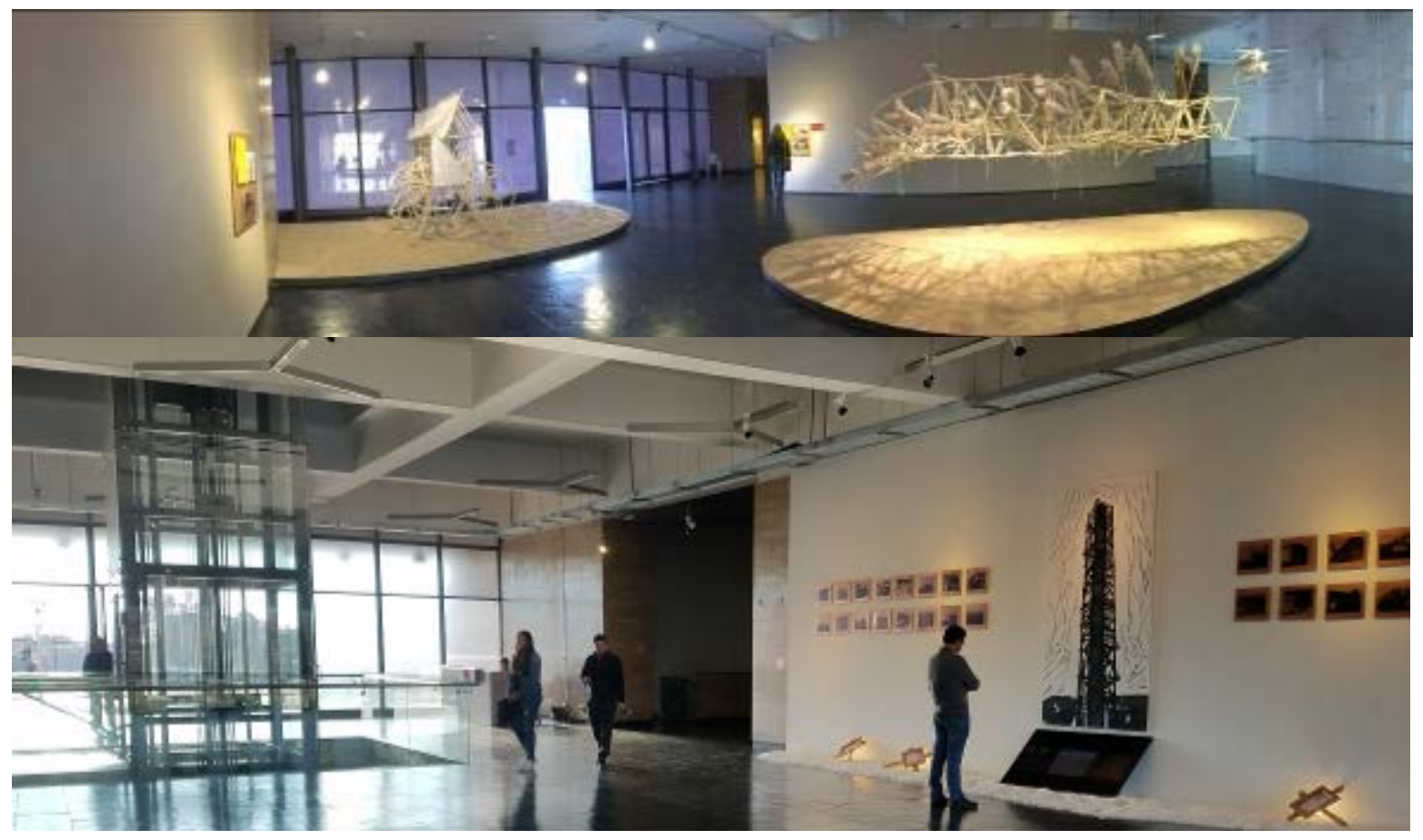




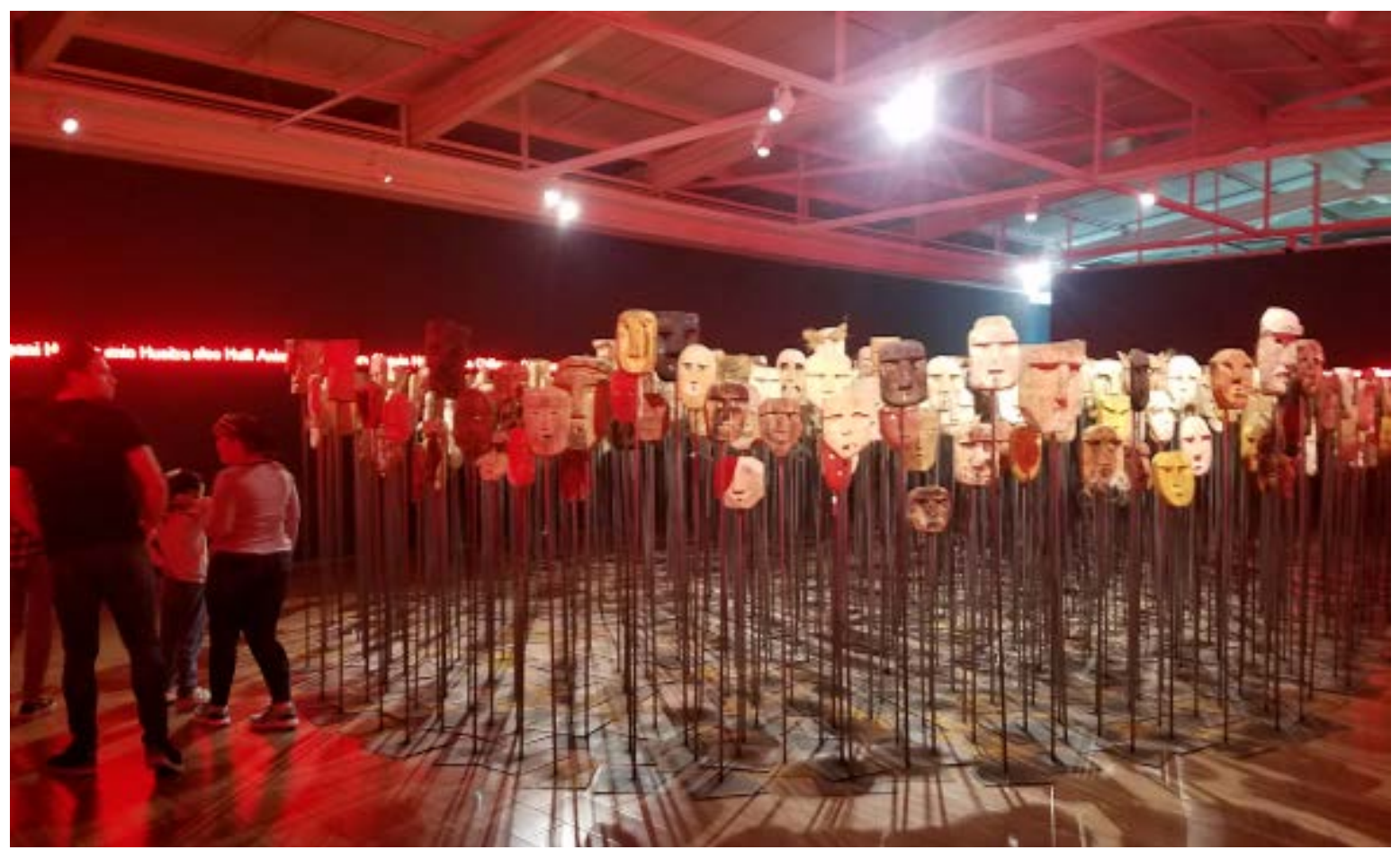

Figs. 10. Salas principales de exposición. Fig. 8. Arriba: Imagen Sala central primera planta, exposición Algoritmos del Viento,Theo Jansen Fig. 10. Centro: Imagen Sala central de la primera planta, exposición Diásporas. Fig. 10. Abajo: Imagen Sala principal segunda planta. exposición Diásporas. Fuente: Elaboración propia.

Los baños para hombres y mujeres se encuentran en pisos diferentes. Lo mismo ocurre con los baños destinados a personas con movilidad reducida. Además, “... puede ser un poco compleja para personas con movilidad limitada, por la cantidad de escaleras que tiene... Habría que habilitar el edificio para personas con movilidad reducida...." (Entrevista N019). Tampoco hay adecuación para personas con discapacidad visual. Sin embargo, una visitante con movilidad reducida indica que al exterior existen rampas y al interior un ascensor que facilitan el desplazamiento.

Durante el fin de semana asisten alrededor de cien personas a las exposiciones. Sin embargo, durante la exhibición de Algoritmos del Viento, de Theo Jansen, la convocatoria fue masiva y en algunos momentos fue necesario regular el ingreso y la permanencia de las personas en las salas.

Al interior del centro se realizan acciones de mediación. Se trata de actividades educativas y de experimentación en torno al arte contemporáneo: se realizan talleres, laboratorios, jornadas y campamentos de educación artística. Siempre se relacionan con la muestra en exposición y finalizan con un recorrido guiado. Son los mediadores quienes conciben y realizan estas actividades. También despliegan creativas estrategias para convocar a los vecinos. Pero, no siempre logran la convocatoria esperada.

Sorprende a los visitantes que habitan la comuna que una exposición del prestigio de Algoritmos del Viento de Theo Jansen haya sido montada en un sector de la ciudad que no es económica ni culturalmente privilegiado. Esto permite el acceso al arte a los habitantes del sector. También se valoran positivamente los montajes y la experiencia de visita, más cuando la exposición se prolonga al patio trasero. Sin embargo, indican que falta mobiliario para el descanso y una cafetería. 


\section{Discusión y conclusiones}

A continuación, se exponen los factores relevantes, luego del entrecruzamiento de las cuatro dimensiones, que permiten establecer la capacidad de transformación del centro.

La existencia de una red de conectividad y la buena calidad del transporte acrecientan en los visitantes la percepción de cercanía del CNACC ubicado lejos del centro de la ciudad y de los centros de arte existentes en Santiago. Esta percepción es compartida por quienes se desplazan en bicicleta, transporte público (buses y metro) y vehículos particulares. Cabe destacar que, la apertura de la estación de metro Cerrillos fue clave para conectar el centro con el resto de la ciudad. El metro es un facilitador que da sentido de conectividad, modernidad y comodidad. Es la existencia de una diversidad de tipos de transportes lo que promueve y agiliza las visitas de personas de distintos sectores, en una ciudad altamente segmentada en términos sociales, culturales y económicos, y lo vincula al sistema urbano. Pese a ello, la conectividad se ve afectada por la inexistencia de señalética que una la salida de la estación del metro con el CNACC, a lo que se suma la ausencia de indicaciones para el ingreso de los vehículos al estacionamiento.

La torre de control, el volumen circular de su arquitectura y el mural de los Cóndores, aseguran la legibilidad y permiten vincular el centro con el hito urbano constituido por el antiguo aeropuerto. Estas imágenes activan la memoria y potencian la identidad comunal. Se suma a esto que, la programación del centro está concebida para visibilizar la edificación original. A saber, algunas de las principales actividades se nominan con terminología vinculada a la aeronáutica: Programa Hélice o Programa Planeadores. Además, algunos de los espacios emblemáticos -como la torre de control y las explanadas de acceso- se utilizan para desarrollar actividades de mediación; y en una de las plazas se exponen objetos de arte vinculados a la aviación. Sin embargo, el color blanco, la forma, el tamaño y escaso contraste de las letras que indican el nombre del centro, y la ausencia de más señalética impiden la correcta legibilidad del CNACC. Otro elemento que afecta a su legibilidad es la existencia de un imaginario de los visitantes respecto de la edificación de los centros de arte como una obra de arte única y monumental que marca la diferencia con las construcciones aledañas e indica su presencia. Se espera que la edificación comunique por sí misma que se trata de un lugar de arte y para el arte.

El hecho que el edificio del CNACC cuente con dos accesos principales favorece la entrada de los visitantes. Esto diversifica las rutas de ingreso: los visitantes que usan transporte público llegan por la avenida Pedro Aguirre Cerda y los visitantes, usuarios de transporte particular, por el Parque Bicentenario. Las franjas de pavimento que conectan el parque con el centro direccionan a los visitantes. La presencia de rampas facilita el ingreso de personas con movilidad reducida y la existencia de un ascensor ubicado al interior del centro favorece la conexión de todas las plantas, a pesar de no ser visibilizado por los visitantes que no requieren de estos dispositivos. Por su parte, el acceso al centro por la avenida Pedro Aguirre Cerda presenta obstáculos: la valla que lo separa de la acera se lee como una prohibición de ingreso y limita la libre circulación de los posibles visitantes; el retranqueo de la fachada genera una sombra que dificulta la visibilidad de la entrada, lo que impide saber si el centro está abierto o cerrado; y, por último, la existencia de una escalera de acceso al edificio se presenta como una barrera física.

El recorrido de los visitantes al interior del centro se ve favorecido por el contraste entre las proporciones de los accesos principales con los de las distintas salas y oficinas, lo que permite diferenciar tres niveles de acceso a los diferentes recintos. Pero, la ausencia de señalética que indique la existencia de salas diferentes y de lo expuesto en ellas, dificulta el libre recorrido. Lo mismo sucede con la percepción de los visitantes respecto de la escasa diferenciación entre los espacios servidores y servidos. Por último, la inexistencia de lugares de permanencia al interior del centro, durante y al final del recorrido, restringe la prolongación de las visitas. 
La flexibilidad se ve favorecida por: la existencia de plazas aledañas que prolongan el espacio expositivo y vinculan el interior del centro con el exterior; la distancia, tanto a nivel horizontal como vertical, entre los elementos estructurales que posibilita la exposición de distintas obras, aunque no las de gran tamaño; y la existencia de iluminación natural en la mayoría de las salas que permite la graduación de la luz de acuerdo a los requerimientos curatoriales.

Si bien se requiere potenciar el vínculo con los visitantes para que el CNACC forme parte de su vida cotidiana, que las actividades conecten el interior con el exterior, que se abran las plazas y que se incorpore nueva señalética, la existencia de los elementos estructurales de la conectividad, accesibilidad, legibilidad, recorridos y permanencias, y flexibilidad, permiten establecer que el Centro Nacional de Arte Contemporáneo de Cerrillos opera como un motor de transformación de un sector desvalorizado de la ciudad.

\section{BIBLIOGRAFIA}

CENTRO NACIONAL DE ARTE CONTEMPORÁNEO CERRILLOS (2016) Catálogo: Una imagen llamada palabra. Recuperado de http://centronacionaldearte.cl/wp-content/uploads/2016/09/catalogo-imagen-llamadapalabra.pdf

CONSEJO NACIONAL DE LA CULTURA Y LAS ARTES (s.f.). Política de fomento de las artes visuales (20102015). Consejo Nacional de la Cultura y las Artes. Chile. Recuperado: https://www.cultura.gob.cl/wpcontent/uploads/2011/11/politica artesvisuales.pdf

CORREA, S. ET.AL. (2001) Historia del siglo XX chileno. Santiago: Editorial Sudamericana.

DE RAMÓN, A. (2000) Santiago de Chile (1541-1991). Historia de una sociedad urbana. Santiago: Editorial Sudamericana.

ELIASH, H. (2006). Portal Bicentenario: breve crónica de un proyecto urbano emblemático. Revista de Arquitectura, 12(13), Pág. 56-58. doi:10.5354/0719-5427.2013.28297

ELIASH, H. (2013) Análisis histórico edificio ex terminal aéreo de Cerrillos. Santiago: s/e.

ESTEBAN, IÑAKI. (2007). El efecto Guggenheim del espacio basura al ornamento. Ed. Anagrama, Barcelona.

GALILEA, S. (2006) "Proyecto Portal Bicentenario". En Revista de Arquitectura. Facultad de Arquitectura y Urbanismo. Universidad de Chile. №13.

GONZÁLEZ AGUAYO, R. (2010). El proyecto "Ciudad del Viento", Portal Bicentenario, Cerrillos: fecundidad de una idea modelo de diseño urbano sustentable. Revista de Urbanismo, (22), Pág. 12-57. doi:10.5354/07175051.2010 .8832

ILUSTRE MUNICIPALIDAD DE CERRILLOS (2011). Plan de Desarrollo Comunal (PLADECO). Recuperado: https://www.mcerrillos.cl/pdf/pladeco-cerrillos-2011.pdf

LAYUNO ROSAS, M. A. (2003). Museos de arte contemporáneo y ciudad. Los límites del objeto arquitectónico. En: Lorente, Jesús Pedro y Almazán, David (Ed.) Museología crítica y arte contemporáneo. Ed. Prensas Universitarias, Zaragoza.

LOBOS BEACH, M., \& MONTEALEGRE KLENNER, A. (2007). El Parque Portal Bicentenario en Santiago de Chile. Revista de Urbanismo, (16). doi:10.5354/0717-5051.2010.298

LYNCH, K. (2006). La imagen de la ciudad. Barcelona: Gustavo Gili.

MILES, M., Huberman, M. \& J. Saldaña (2014). Qualitative data analysis: a methods sourcebook. Los Ángeles: SAGE.

Ministerio de las Culturas, las Artes y el Patrimonio inaugura Centro Nacional de Arte Contemporáneo Cerrillos con homenaje a José Balmes (2016). Recuperado: https://www.cultura.gob.cl/eventos-actividades/centrocerrillos-abre-sus-puertas-con-exposicion-que-resume-medio-siglo-de-arte-contemporaneo-chileno/ 
PIRES, A. (1997). Échantillonnage et recherche qualitative : essai théorique et méthodologique. En J. Poupart, J.P. Deslauriers, L.H. Groulx, A. Lapirrière, R. Mayer, \& A. Pires La recherche qualitative. Enjeux épistémologiques et méthodologiques (pp. 113-167). Québec: Gaëtan Morin Éditeur.

RINKE, S. (2013) Encuentros con el Yanqui: Norteamericanización y cambio sociocultural en Chile 1898-1990. Santiago: Dibam.

VALDIVIA, V. (2015) La democracia dictatorial pinochetista: regionalización y municipios. Avances del Cesar, 12, 171-187.

VALENZUELA, F.A; ESPINOSA, A; MADERO-CABIB, I; MOYANO, C; ORTIZ, F. (2015). "Los museos de arte como mecanismos de inclusión y exclusión social en el arte y en la sociedad: un estudio de caso en Chile". Boletim do Museo Paraense Emilio Goeldi. Ciencias Humanas. V. 10. N. 3. p. 723-737.

ZUNZUNEGUI, S. (1990). Metamorfosis de la mirada. El museo como espacio del sentido. Alfar, Sevilla. 